\title{
Mengupas Pengaruh Kompetensi Individu Dan Budaya Organisasi Terhadap Kinerja Karyawan Pada Perusahaan e-Commerce di Indonesia
}

\author{
Nopriadi Saputra, Farah Maulida, Pramudhita Ekaputri Dewanto \\ Management Department, BINUS Business School Undergraduate Program, \\ Bina Nusantara University \\ email: nopriadiaputra@gmailcom
}

Received: 13 August 2021; Revised: 02 October 2021; Accepted: 14 December 2021

DOI: http://dx.doi.org/10.37905/aksara.8.1.179-186.2022

\begin{abstract}
Abstrak
Penelitian ini bertujuan untuk mengetahui apakah kompetensi individu dan budaya organisasi memiliki pengaruh terhadap kinerja karyawan di Elevenia. Metode pengumpulan data yang digunakan dalam penelitian ini yaitu dengan menyebarkan kuesioner kepada karyawan dan diperoleh responden sebanyak 140 orang. Metode analisis yang digunakan adalah analisis regresi berganda dengan menggunakan software IBM SPSS Statistics 22 sebagai pengolahan data. Hasil penelitian menunjukkan bahwa kompetensi individu dan budaya organisasi berpengaruh secara simultan terhadap kinerja. Hasil penelitian secara parsial menunjukkan bahwa terdapat pengaruh yang signifikan pada kompetensi individu terhadap kinerja karyawan, sedangkan budaya organisasi tidak memiliki pengaruh yang signifikan terhadap kinerja karyawan.
\end{abstract}

Kata Kunci: kompetensi individu, budaya organisasi, kinerja karyawan.

\section{PENDAHULUAN}

Pada era globalisasi ini, masyarakat tidak hanya menggunakan internet untuk mencari informasi, namun juga sebagai media untuk bersosialisasi bahkan melakukan kegiatan perdagangan secara online. Karena itu, bidang perdagangan sangat dipengaruhi oleh perkembangan teknologi. Indonesia merupakan pasar dengan pertumbuhan e-commerce yang cukup tinggi dari tahun ke tahun. Sejak tahun 2014, Euromonitor menyatakan bahwa penjualan online di Indonesia telah mencapai US\$1,1 miliar. Badan Pusat Statistik (BPS) juga menjelaskan bahwa peningkatan e-commerce di Indonesia mencapai $17 \%$ dengan total jumlah usaha e-commerce yang mencapai 26,2 juta unit (Rahayu, 2019).

Merchant Machine lembaga riset asal Inggris telah mempublikasikan daftar sepuluh negara dengan pertumbuhan e-commerce tercepat di dunia. Pada tahun 2018, Indonesia dengan pertumbuhan $78 \%$ berada pada barisan negara-negara tersebut. Jumlah pengguna internet di Indonesia yang telah mencapai lebih dari 100 juta pengguna menjadi salah satu faktor pendukung yang mendorong pertumbuhan $e$ commerce. E-commerce merupakan proses transaksi barang atau jasa pada World Wibe Internet dalam bentuk konsep baru (Hari Widowati, 2019).

Elevenia merupakan salah satu e-commerce di Indonesia yang menggunakan konsep open marketplace sebagai penyedia jasa belanja online. Hal tersebut akan memberikan kemudahan dan keamanan berbelanja online bagi para pengguna. Elevenia telah didirikan pada tahun 2013 dan secara resmi menjalankan bisnisnya sebagai pasar pada tahun 2014. PT. XL Planet (Elevenia) kini telah menjadi perusahaan start-up yang melakukan transformasi bisnis menjadi bagian dari perkembangan ekosistem digital dari perusahaan di Indonesia. Dengan mengandalkan 
budaya inovasi, Elevenia ditantang untuk menghasilkan produk dan layanan digital yang bermanfaat bagi para pemangku kepentingan dengan didukung oleh suasana kerja yang nyaman dan menyenangkan. Metode umum yang diterapkan oleh Elevenia sendiri yaitu work life balance, Elevenia yakin dengan menerapkan metode tersebut karyawan dapat lebih produktif dan berkinerja tinggi (Linkedin.com/elevenia, 2019).

Saat ini, persaingan antar perusahaan semakin kuat. Oleh karena itu, Elevenia harus mengoptimalkan setiap organisasi tentu mengharapkan suatu keberhasilan, untuk mencapai keberhasilan tersebut membutuhkan adanya kinerja yang berkualitas Saat ini, seringkali masalah yang bermunculan berkaitan dengan ketenagakerjaan terutama mengenai kinerja pegawai. Oleh karena itu, masalah yang berkaitan dengan kinerja perlu dicari jalan keluarnya. Menurut Dessler, kinerja merupakan perbandingan antara prestasi kerja, yaitu perbandingan antara standar yang diharapkan dan hasil kerja. Sedangkan menurut Siagian, kinerja adalah kegiatan operasional karyawan, suatu bagian organisasi, dan bagian yang berdasarkan kriteria yang ditetapkan yang merupakan konsep universal (Kristanto, 2015).

Salah satu faktor pembentuk kinerja terbaik adalah kemampuan yang juga dapat dimaknai sebagai kompetensi. "competence includes the aptitude necessary to enhance basic abilities and to raise job performance to a higher level". Definisi tersebut menjelaskan bahwa kompetensi sebagai suatu faktor yang dibutuhkan untuk meningkatkan kinerja dan kemampuan dasar menuju pada tingkat yang lebih tinggi (Rande, 2016).

Budaya organisasi merupakan norma - norma dan kebiasaan yang dapat diterima sebagai suatu kebenaran oleh semua orang dalam organisasi. Budaya organisasi menjadi acuan bersama di antara manusia dalam berinteraksi di sebuah organisasi. Apabila orang - orang bergabung dalam sebuah organisasi, maka mereka akan membawa nilai - nilai dan kepercayaan yang telah diajarkan kepada mereka (Ariesta, 2017).

Elevenia sendiri selalu melakukan penilaian kinerja rutin setiap tahun. Penilaian kinerja dilakukan secara rutin agar perusahaan dapat terus melakukan evaluasi dan memantau pergerakan kualitas kinerja dari anggota karyawannya, apakah mengalami peningkatan atau penurunan dari tahun yang sebelumnya. Tujuan evaluasi kinerja yang dilakukan elevenia, diantaranya: (1) untuk meningkatkan kinerja organisasi, tim, dan individu. (2) untuk mengklarifikasi harapan tentang apa yang harus dicapai individu dan tim, (3) untuk mengembangkan keterampilan dan kompetensi individu karyawan, (4)Untuk menyediakan metode penilaian yang lebih objektif dan adil, (5) untuk mengetahui apakah nilai perusahaan telah tercerminkan, dan (6) untuk memberdayakan individu dalam mengelola kinerja dan pembelajaran mereka sendiri. (Fernandi Mahendrasusila, 2019).

Dapat diketahui bahwa pada tahun 2017 karyawan yang tidak mencapai standar kerja perusahaan dengan total 37,2\%, pada tahun 2018 sebesar 33\%, dan pada tahun 2019 mencapai 41,7\%. Hal tersebut menunjukkan bahwa grafik mengalami ketidakstabilan bahkan pada tahun terakhir mengalami peningkatan. Sehingga, masih banyak karyawan di Elevenia yang kinerjanya tidak mencapai standar perusahaan. Melihat pentingnya kinerja karyawan dalam mewujudkan tujuan perusahaan, kondisi seperti ini membutuhkan perhatian dari perusahaan. 


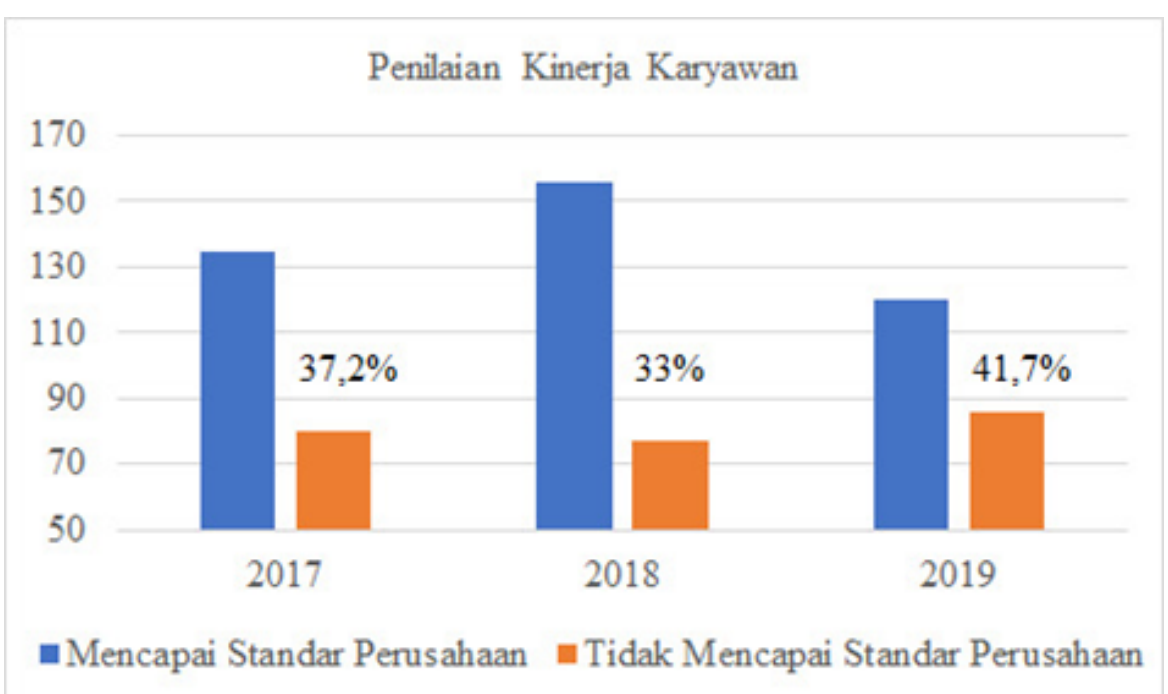

\section{Gambar 1 Grafik Penilaian Kinerja Karyawan} Sumber: Elevenia, unit Human Resources (2020)

Elevenia selalu mengharapkan kompetensi yang kuat pada karyawannya untuk mendorong kualitas kinerja perusahaan. Elevenia sendiri telah memfasilitasi beberapa program yang dapat mendukung peningkatan kompetensi karyawan, seperti melakukan training, sesi e-learning, hingga employee development coaching. Namun, dari kegiatan yang telah dilakukan, jumlah karyawan yang mengikuti program yang telah difasilitasi perusahaan tidak selalu banyak peminatnya, bahkan apabila terdapat program yang diwajibkan pun juga seringkali mengalami permasalahan yang sama. Kualitas karyawan masih banyak yang belum menyadari mengenai penguasaan perkembangan bisnis dan pencapaian target perusahaan. Sehingga, hasil yang terealisasikan seringkali tidak sesuai dengan target yang diharapkan perusahaan serta masih kurangnya pengetahuan dan keterampilan karyawan yang mendukung pekerjaannya (Fernandi Mahendrasusila, 2019).

Seorang karyawan yang memiliki kompetensi yang tinggi seperti pengetahuan, keterampilan, kemampuan, dan sikap yang sesuai dengan jabatannya selalu terdorong untuk bekerja secara efisien, efektif, dan produktif. Hal tersebut dapat terjadi karena dengan kompetensi yang dimiliki karyawan bersangkutan dengan kemampuan untuk melaksanakan tugas-tugas yang dibebankan kepadanya, karena keberhasilan suatu organisasi dipengaruhi oleh sumber daya yang terdapat di dalam organisasi tersebut. Sumber daya manusia sangat memiliki peran yang penting guna mencapai sasaran organisasi. Untuk itu, diperlukan sumber daya yang memadai dalam suatu organisasi. Sumber daya manusia yang memadai dapat dilihat dari kompetensi yang dimiliki setiap pegawai di dalam suatu perusahaan (Rande, 2016).

Perusahaan Elevenia juga telah melihat tantangan dalam bisnis start up, maka perusahaan menerapkan corporate value yang menjadi landasan budaya organisasi dalam tiga hal yaitu, challenging, innovation, dan happiness. Dengan tiga komponen tersebut Elevenia berharap karyawan dapat lebih bahagia dan kreatif karena didukung oleh lingkungan yang mendukung pertumbuhannya. Sedangkan, permasalahan yang terjadi yaitu masih kurangnya kontribusi karyawan dalam mendukung budaya inovatif. Banyak karyawan yang tetap bekerja secara monoton dan kurang mengeksplorasi ide 
baru dalam melakukan pekerjaannya. Karyawan juga dinilai masih belum berani dalam mengambil resiko (Fernandi Mahendrasusila, 2019).

Dengan pergerakan industri digital yang terus berubah dan berkembang, serta perubahan yang tidak membutuhkan waktu lama, perusahaan dalam bidang digital tentunya akan terus berlomba-lomba untuk mengambil posisi siapa yang memimpin dan siapa yang tertinggal. Budaya yang kuat dan pengelolaan karyawan yang baik adalah kekuatan berkompetisi dengan pesaing. Agar perusahaan Elevenia dapat terus bertahan, secara otomatis perusahaan diwajibkan untuk terus menghasilkan sesuatu yang baru. Organisasi yang inovatif dan kreatif akan memiliki peluang yang lebih besar untuk meraih kesuksesan dibandingkan dengan organisasi lain yang pasif dan reaktif. Cepatnya perubahan dari lingkungan eksternal tentu mendorong perusahaan mengenai perlunya permahan terhadap eksistensi budaya organisasi yang sesuai (Hidayah, Kemal, Kusumaningrum, Mayahayati, Wismono, Fani Heru, Amarullah, 2018).

Berdasarkan uraian di atas, maka tujuan penelitian ini yaitu untuk mengetahui apakah kompetensi individu berpengaruh signifikan terhadap kinerja karyawan, budaya organisasi berpengaruh signifikan terhadap kinerja karyawan, serta mengetahui apakah kompetensi individu dan budaya organisasi berpengaruh secara simultan terhadap kinerja karyawan di Eleveni

\section{METODE PENELITIAN}

Penelitian ini menggunakan penelitian kuantitatif. Ninit Alfianika (2018:26) menjelaskan bahwa dalam penelitian kuantitatif akan banyak dituntut menggunakan angka, mulai dari pengumpulan data, penafsiran, dan penampilan hasilnya. Dalam memperoleh data primer, peneliti menggunakan hasil penyebaran kuesioner pada sampel yang telah ditentukan berupa data mentah yang berisi tanggapan responden mengenai kompetensi individu, budaya organisasi, dan kinerja karyawan pada karyawan Elevenia. Sedangkan, untuk data sekunder, peneliti menggunakan studi pustaka yang berasal dari buku, jurnal, dan literatur lain untuk mengartikan suatu interpretasi dari objek penelitian yang diteliti.

Populasi yang digunakan dalam penelitian yaitu karyawan dari perusahaan Elevenia yang berjumlah 206 karyawan. Peneliti menggunakan teknik random sampling yaitu pengambilan acak kelompok suatu penelitian tanpa mempertimbangkan strata populasi. Untuk penentuan jumlah sampel, menggunakan rumus Slovin dan diperoleh hasil minimal sampel yaitu 136 orang. Sampel yang didapat dari hasil penyebaran kuesioner berjumlah 140 orang. Penelitian ini menggunakan analisis regresi linear berganda untuk menjawab hipotesis penelitian. Metode analisis yang digunakan dalam penelitian ini terdiri dari uji validitas, uji reliabilitas, kemudian uji asumsi klasik yaitu uji normalitas, multikoliniearitas, dan heteroskedastisitas, dan dilanjutkan dengan uji analisis regresi linear berganda yang terdiri dari uji koefisien determinasi, berupa uji t, dan uji $f$.

\section{HASIL DAN PEMBAHASAN}

Data yang terkumpul dari hasil kuesioner kemudian akan ditabulasi dengan perangkat lunak SPSS. Langkah awal adalah menguji validitas indikator dari masingmasing variabel. Instrumen yang digunakan di penelitian ini akan diuji melalui uji validitas seperti ditunjukkan pada tabel berikut ini. 
Tabel 1 Uji Validitas Variabel Kompetensi Individu

\begin{tabular}{|c|c|c|c|c|}
\hline Variabel & $\begin{array}{l}\text { Item } \\
\text { Pertanyaan }\end{array}$ & $\begin{array}{l}\mathrm{R} \\
\text { Hitung }\end{array}$ & Simbol & $\begin{array}{l}\mathrm{R} \\
\text { Tabel }\end{array}$ \\
\hline \multirow{10}{*}{$\begin{array}{l}\text { Kompetensi } \\
\text { Individu } \\
\text { (X1) }\end{array}$} & PT01 & 0,902 & $>$ & 0,17 \\
\hline & РT02 & 0,917 & $>$ & 0,17 \\
\hline & KT01 & 0,711 & $>$ & 0,17 \\
\hline & KT02 & 0,770 & $>$ & 0,17 \\
\hline & KT03 & 0,703 & $>$ & 0,17 \\
\hline & KT04 & 0,819 & $>$ & 0,17 \\
\hline & KT05 & 0,727 & $>$ & 0,17 \\
\hline & SM01 & 0,790 & $>$ & 0,17 \\
\hline & SM02 & 0,808 & $>$ & 0,17 \\
\hline & SM03 & 0,827 & $>$ & 0,17 \\
\hline \multirow{8}{*}{$\begin{array}{l}\text { Budaya } \\
\text { Organisasi } \\
\text { (X2) }\end{array}$} & CL01 & 0,874 & $>$ & 0,17 \\
\hline & CL02 & 0,919 & $>$ & 0,17 \\
\hline & CLO3 & 0,919 & $>$ & 0,17 \\
\hline & IN01 & 0,862 & $>$ & 0,17 \\
\hline & IN02 & 0,895 & $>$ & 0,17 \\
\hline & IN03 & 0,891 & $>$ & 0,17 \\
\hline & HP01 & 0,924 & $>$ & 0,17 \\
\hline & HP02 & 0,952 & $>$ & 0,17 \\
\hline \multirow{10}{*}{$\begin{array}{l}\text { Kinerja } \\
\text { Karywan } \\
(\mathrm{Y})\end{array}$} & HK01 & 0,677 & $>$ & 0,17 \\
\hline & HK02 & 0,811 & $>$ & 0,17 \\
\hline & HK03 & 0,718 & $>$ & 0,17 \\
\hline & HK04 & 0,750 & $>$ & 0,17 \\
\hline & BK01 & 0,797 & $>$ & 0,17 \\
\hline & BK02 & 0,882 & $>$ & 0,17 \\
\hline & BK03 & 0,879 & $>$ & 0,17 \\
\hline & WP01 & 0,868 & $>$ & 0,17 \\
\hline & WP02 & 0,922 & $>$ & 0,17 \\
\hline & WP03 & 0,847 & $>$ & 0,17 \\
\hline
\end{tabular}

Berdasarkan hasil pengolahan data menggunakan SPSS, maka diperoleh data pada tabel di atas, bahwa seluruh butir pertanyaan pada variabel kompetensi individu, budaya organisasi, dan kinerja karyawan memiliki nilai $\mathrm{R}$ hitung $>\mathrm{R}$ tabel, sehingga dapat disimpulkan bahwa seluruh pertanyaan dinyatakan valid. Setelah melakukan uji validitas dan butir instrumen dinyatakan valid, maka tahap selanjutnya adalah melakukan uji reliabilitas. Dasar pengambilan keuputusan pada uji reliabilitas sebagai berikut: (1) Jika Cronbach's Alpha > 0,60, maka variabel dinyatakan reliabel, (2) Jika Cronbach's Alpha $<0,60$, maka variabel dianggap tidak reliabel.

Berikut hasil uji reliabilitas pada variabel kompetensi individu (X1), budaya organisasi (X2), dan kinerja karyawan (Y) menggunakan SPSS 22: 
Tabel 2 Hasil Uji Reliabilitas

\begin{tabular}{llll}
\hline Variabel & Indikator & Cronbach's Alpha & Keterangan \\
\hline Kompetensi & Pengetahuan & 0,898 & Reliabel \\
\cline { 2 - 4 } Individu & Keterampilan & 0,792 & Reliabel \\
\cline { 2 - 4 } & Sikap Mental & 0,829 & Reliabel \\
\hline \multirow{2}{*}{$\begin{array}{l}\text { Budaya } \\
\text { Organisasi }\end{array}$} & Challenging & 0,864 & Reliabel \\
\cline { 2 - 4 } & Innovation & 0,857 & Reliabel \\
\cline { 2 - 4 } & Happiness & 0,910 & Reliabel \\
\hline Kinerja & Hasil Kerja & 0,791 & Reliabel \\
Karyawan & Bentuk Kontribusi & 0,847 & Reliabel \\
\cline { 2 - 4 } & Waktu Periode & 0,856 & Reliabel \\
\hline
\end{tabular}

Tabel 3 Koefisien Regresi

\begin{tabular}{|c|c|c|c|c|c|c|}
\hline \multicolumn{7}{|c|}{ Coefficients $^{\mathrm{a}}$} \\
\hline \multirow{2}{*}{\multicolumn{2}{|c|}{ Model }} & \multicolumn{2}{|c|}{$\begin{array}{l}\text { Unstandardized } \\
\text { Coefficients }\end{array}$} & $\begin{array}{l}\text { Standardized } \\
\text { Coefficients }\end{array}$ & \multirow[t]{2}{*}{$\mathrm{T}$} & \multirow[t]{2}{*}{ Sig. } \\
\hline & & $\mathrm{B}$ & Std. Error & Beta & & \\
\hline \multirow{3}{*}{1} & (Constant) &, 892 &, 302 & & 2,956 &, 004 \\
\hline & KOMPETENSI &, 650 &, 073 & 609 & 8,962 &, 000 \\
\hline & BUDAYA &, 079 &, 045 &, 121 & 1,776 &, 078 \\
\hline
\end{tabular}

a. Dependent Variable: KINERJA

Persamaan regresi yang dihasilkan adalah:

$\mathrm{Y}=0,892+0,650 \mathrm{X} 1+0,079 \mathrm{X} 2$

Berdasarkan hasil uji t, nilai signifikansi untuk variabel kompetensi individu yaitu $0,000<0,05$ dan diperoleh nilai t hitung sebesar 8,962 > t tabel 1,86. Sehingga, hipotesis pertama dapat diterima. Artinya, kompetensi individu berpengaruh signifikan terhadap kinerja karyawan. Hal ini dapat dibuktikan bahwa secara parsial kompetensi individu memiliki pengaruh yang signifikan terhadap kinerja karyawan di Elevenia. Sedangkan, nilai signifikansi untuk variabel budaya organisasi yaitu 0,078>0,05. Selain itu, pada variabel budaya organisasi juga diperoleh nilai t hitung sebesar 1,776 < $\mathrm{t}$ tabel 1,86. Sehingga, dapat disimpulkan bahwa hipotesis kedua ditolak. Artinya, secara parsial budaya organisasi tidak berpengaruh signifikan terhadap kinerja karyawan.

Uji $\mathrm{F}$ bertujuan untuk mengetahui signifikansi dari variabel independen (kompetensi individu dan budaya organisasi) terhadap variabel dependen (kinerja karyawan) secara simultan.

Tabel 4 Hasil uji F

\begin{tabular}{lllllll}
\hline ANOVA $^{\mathbf{a}}$ & & & & & \\
\hline & & Sum & of & Mean & & \\
Model & Squares & Df & Square & F & Sig. \\
\hline 1 & Regression & 3,039 & 1 & 3,039 & 15,026 &, $000^{\mathrm{b}}$ \\
\cline { 2 - 7 } & Residual & 27,910 & 138 &, 202 & & \\
\cline { 2 - 6 } & Total & 30,949 & 139 & & & \\
\hline
\end{tabular}

a. Dependent Variable: KINERJA 


\section{b. Predictors: (Constant), BUDAYA}

Berdasarkan hasil uji f, diperoleh nilai signifikansi $0,000<0,05$ dan dihasilkan nilai f hitung sebesar 15,026 > f tabel 3,06. Maka, hipotesis ketiga dapat diterima. Sehingga, dapat disimpulkan bahwa kompetensi individu dan budaya organisasi berpengaruh secara simultan terhadap kinerja karyawan di Elevenia.

\section{KESIMPULAN}

Berdasarkan hasil analisis data, maka penelitian ini menetapkan beberapa kesimpulan sesuai dengan temuan yang diperoleh dan dibahas sebelumnya. Kesimpulan penelitian ini adalah: (1) hipotesis pertama dapat diterima. Secara parsial, kompetensi individu berpengaruh signifikan terhadap kinerja karyawan di Elevenia, (2) hipotesis kedua ditolak. Secara parsial, budaya organisasi tidak berpengaruh terhadap kinerja karyawan, (3) hipotesis ketiga dapat diterima. Kompetensi individu dan budaya organisasi berpengaruh secara simultan terhadap kinerja karyawan.

Dari hasil analisis dan kesimpulan pada penelitian ini, maka penulis memberikan saran sebagai berikut: (1) perusahaan diharpakan dapat memberikan sosialisasi lebih kepada karyawan terkait informasi dan perkembangan perusahaan. Selain itu, perusahaan juga dapat membantu meningkatkan kompetensi karyawan melalui program-program pelatihan, perencana, dan penilaian, (2) perusahaan dapat memberikan kesempatan penugasan tertentu pada karyawan inovatif atau bahkan dengan memberikan reward. Hal tersebut dapat membuat karyawan merasa lebih dihargai dan dapat membuat mereka terdorong untuk menjadi lebih inovatif, (3) Dengan didukung oleh suasana kantor yang terbuka, seluruh karyawan juga diharapkan dapat terbuka untuk didengar dan didengarkan. Karena dari kegiatan yang melibatkan orang banyak, terdapat sudut pandang lain yang dapat dijadikan gagasan terhadap pencapaian target.

\section{REFERENSI}

Ariesta, I. (2017). Pengaruh Kecerdasan Emosional Dan Organizational Citizenship Behavior (OCB) Terhadap Kinerja Peternak Ayam Ras Pedaging. JBMP (Jurnal Bisnis, Manajemen Dan Perbankan), 2(2), 1-20.

Fernandi Mahendrasusila. (2019). Informasi Mengenai Elevenia. Jakarta.

Hari Widowati. (2019). Indonesia Jadi Negara dengan Pertumbuhan E-Commerce Tercepat di Dunia. Retrieved from https://databoks.katadata.co.id website: https://databoks.katadata.co.id/datapublish/2019/04/25/indonesia-jadi-negaradengan-pertumbuhan-e-commerce-tercepat-di-dunia

Hidayah, Kemal, Kusumaningrum, Mayahayati, Wismono, Fani Heru, Amarullah, R. (2018). AKTUALISASI BUDAYA INOVASI PADA ORGANISASI SEKTOR PUBLIK. Jurnal Borneo Administrator, 14(1), 35-52.

Kristanto, H. (2015). Keadilan organisasional, komitmen organisasional, dan kinerja karyawan. 17(1), 86-98.

Linkedin.com/elevenia. (2019). Company Profile Elevenia. Retrieved from 2013 website: https://www.linkedin.com/company/elevenia/about/

Rahayu, N. (2019). Pertumbuhan E-Commerce Pesat di Indonesia. Retrieved from www.wartaekonomi.co.id website: 
https://m.wartaekonomi.co.id/berita216302/pertumbuhan-e-commerce-pesat-diindonesia.html

Rande, D. (2016). Pengaruh Kompetensi Terhadap Kinerja Pegawai Pada Dinas Perhubungan, Komunikasi Dan Informatika Kabupaten Mamuju Utara. Katalogis, 4(2), 101-109. 